\title{
A Marca Rio: o turismo nos documentários sobre a cidade $^{1}$
}

Ricardo Ferreira Freitas ${ }^{2}$, Ana Teresa Gotardo ${ }^{3}$ e Cristina Nunes Sant'anna 4

$1 \quad$ Parte deste artigo foi apresentada no XXIV Compós, em junho de 2015. em estágio sênior, com bolsa da Capes, na Université Paul Valéry - Montpellier III. rfreitas@uerj.br 


\section{Resumo}

O artigo trata da cidade do Rio de Janeiro como marca, memória e centro turístico, abordando dois documentários estrangeiros de televisão sobre turismo: 1000 places to see before you die, estadunidense, exibido pela primeira vez na rede TLC em 2007 e baseado em livro homônimo; e Brazil with Michael Palin, transmitido em 2012 pela rede britânica BBC. As exibições apresentam clichês sobre o Brasil e o Rio de Janeiro como cidade-mercadoria. Por esse viés, a cidade do Rio e a Marca Rio se reelaboram e influenciam a produção de conteúdos sobre o imaginário e a memória, consolidando a visão turística clássica.

\section{Palavras-chave}

Comunicação, memória, cidade, marca, megaeventos.

\section{Abstract}

The article is about the city of Rio de Janeiro as a brand, a memory, and a tourism center, approaching two foreign television documentaries about tourism: 1000 places to see before you die, from the United States, first aired on the TLC network in 2007, and based on a homonymous book; and Brazil with Michael Palin, broadcasted in 2012 by BBC. Both feature clichés about Brazil, and Rio de Janeiro as a city-commodity. From the same point of view, the city of Rio and the Rio brand are being redesigned, also influencing the production of content on the imaginary and memory, consolidating the classic tourist view.

\section{Keywords}

Communication, memory, city, branding, mega events. 


\section{Introdução}

A cidade, suas marcas e memória associadas à Marca Rio, construída por diferentes variáveis, como o cotidiano exótico, as belezas naturais, o consumo turístico e a dita violência vista por estrangeiros serão tema deste artigo. Nesta análise, trataremos de dois documentários seriados de televisão sobre turismo: 1000 places to see before you die, estadunidense, exibido pela primeira vez na rede TLC em 2007 e baseado em livro homônimo; e Brazil with Michael Palin, transmitido em 2012 pela rede britânica BBC. Ambos vislumbram uma ideia de Brasil baseada em clichês que vendem, mais do que nunca, o Rio de Janeiro como cidade-mercadoria (SÁNCHEZ, 2010) - tanto que, em uma das cenas do documentário da BBC, é possível ver (enquanto Michael Palin caminha no metrô) um anúncio institucional do governo do estado do Rio de Janeiro ao fundo, cujo slogan é "Rio de Janeiro: marca registrada do Brasil".

Sedutores paradoxos turísticos como natureza e cosmopolitismo, ou riqueza e pobreza, são integrantes do mix de marketing que compõe e ronda os negócios ligados ao imaginário carioca. Nos documentários selecionados, os corpos, as favelas, as praias e o mercado são apresentados junto a novos clichês associados à cidade, como a pacificação e os legados dos megaeventos. A Marca Rio se reelabora e influencia a produção de conteúdos sobre o imaginário carioca.

As britadeiras, as buzinas, as vozes humanas, os celulares, entre tantos outros elementos comunicacionais, contribuem para os significados do cotidiano urbano. Significados repletos de conflitos, dissensos e mal-entendidos, mas, em geral, cheios de afetos e sentimentos. Simmel (2004) assinalou muito bem esses aspectos em sua "teoria do conflito", na qual interpreta o conflito como conteúdo fundamental à organização da sociedade (p. 355), visto que une, na mesma luta, os seus opostos, evidenciando a impossibilidade de oposição sem adesão. Uma luta constante pela harmonia mesmo na discordância. Os dois documentários abordam esses conflitos de forma superficial, mas deixam claro que eles existem nos mais diversos níveis, mesmo na praia, espaço celebrado como democrático. 


\section{City branding e a Marca Rio}

A construção de uma marca para uma cidade ou território tem conquistado, especialmente na última década, adeptos ao redor do mundo. Com base no marketing, as teorias relacionadas a city branding, place branding ou destination branding, de modo geral, consideram que "[...] os territórios competem entre si e precisam se posicionar com diferenciação e preferência na mente dos potenciais decisores para que, quando chegue o momento de eleger, eles tenham claro que a proposta de valor de um território é melhor que a de seus competidores." (GARCÍA; GÓMEZ; MOLINA, 2013, p. 111). Com isso, buscam-se ativos intangíveis para a construção de uma reputação mercadológica de marca, entendida por esses autores como "a representação perceptual das ações passadas e expectativas futuras que descrevem o atrativo geral do território para seus grupos de interesse em comparação a seus competidores." (Ibid., p. 112). Assim, o marketing de destino é componente essencial para atração de investidores, capital internacional, empresas, conhecimento, novos habitantes, turistas, visitantes, estimulando a venda de produtos e serviços locais (JANSSON; POWER, 2006). Para tanto, Martínez (2007) relata as formas de comunicação eficazes de gestão da marca de uma cidade ou país para a construção de uma identidade, imagem e reputação: a comunicação organizativa e a comunicação de marketing. A primeira diz respeito, segundo a autora, a "fortalecer o conhecimento dos cidadãos sobre sua cidade ou país, assegurar valores e princípios e, por fim, reafirmar a cultura. A gestão desta forma de comunicação é a chave do êxito, já que permite motivar, sensibilizar e integrar a cidadania como os protagonistas deste processo de construção da marca." (Ibid., p. 95).

Já a comunicação de marketing objetiva "criar e manter a identidade e o prestígio para alcançar um reconhecimento, posicionamento e reputação entre seus públicos." (loc. cit.). A ideia central de city marketing, segundo a autora, é tratar a cidade como uma empresa, que faz parte de um mercado de cidades e busca obter êxito dentro dele. Para tal, utiliza-se de ferramentas de gestão 
empresarial para desenhar suas estratégias como as ferramentas de marketing e a construção de uma marca forte para a cidade, estado ou país.

No que diz respeito especificamente ao branding - conceito que entendemos aqui como o processo de construção de uma marca para torná-la visível e identificável - consideramos que as marcas estabelecem identidade com quem as usa, aprecia ou deseja, além de conceitos como valor, fidelidade e afeto. A identidade de uma marca inclui ainda atributos como qualidade, tradição, emoção, alegria e criatividade. Valor, poder e força de uma marca estão, então, registrados como símbolos no engenho da memória humana. Ao observar o valor de um signo marcário, estaríamos observando que tipo de valor comunicacional ele possui, pois toda narrativa se calca em signos, em marcas de memória comunicadas pela linguagem nas mais diferentes mídias. Esse é o processo pelo qual sujeito e cultura se interligam e compartilham marcas que afetam ambos, construindo uma relação social que reflete sobre experiências do passado com o olhar aguçado do presente, já que a memória atua sobre o tempo socializado e domado pela cultura. Segundo Bosi (2009, p. 39), "A memória é um cabedal infinito do qual só registramos um fragmento." Fundem-se, então, nesse exercício de comunicação e linguagem, conhecimento, percepção, afetos e imaginação.

Uma marca também atua na esfera do mágico, do que enfeitiça, fazendose gravar como um nome ou uma imagem, encantados, na mente humana; a identidade que podemos estabelecer é capaz de desencadear uma profusão de associações em nós. E é por intermédio de tais associações comunicacionais que se pode começar a investigar a função, a importância e os feitos de uma marca nos meandros da sociedade. A Marca Rio se encaixa nesse exercício antropológico de símbolos e metalinguagem, sendo um ativo intangível que vive na memória de todos, cariocas ou não. Ao se guardar na memória uma marca, inicia-se um processo de comunicação e cultura que entrelaça sentimento e racionalidade, tendo como pano de fundo a construção da memória. Sobre isso, Marcelo Franz afirma que 
a palavra latina "corde" (coração) pode remeter a um sentido primordial de afetividade (no caso, memória afetiva) que é mais destacado que nos outros termos. Isso persiste mesmo quando se sabe que, diferentemente do que pensavam os antigos, o coração não só não tem "afetos" como não os guarda. A afetividade do coração é hoje uma metáfora aplicável à prevalência do intuitivo sobre o racionalizado, e todos sabemos que a memória é em muitos sentidos assim (FRANZ, 2006, p. 46).

Somente uma marca guardada e resguardada na memória, que é construída, será capaz de se tornar autônoma, apta para expressar a contento a própria força e o poder que simboliza e carrega. A subjetividade passa a fazer parte do jogo entre memória, racionalidade e afetos, fortalecendo a própria essência da marca e sua singularidade. São as marcas que carregamos em nossa memória que definem os tipos de escolhas que fazemos, pois, no decorrer desse complexo processo que envolve formas e formatos de comunicação e expressão cultural, estará estabelecida uma relação de confiança e sintonia que será prontamente memorizada. Por isso, a Marca Rio, representada na geografia e na cultura da cidade de São Sebastião do Rio de Janeiro, representa igualmente um ativo intangível de valor considerável. Talvez seja por isso que a cidade ocupa o sétimo lugar de uma lista com as 25 cidades mais poderosas do mundo, publicada pelo jornal The Guardian. Los Angeles, nos EUA, encabeça a lista (JORNAL O GLOBO, 2014).

Não por acaso, o governo do Estado do Rio de Janeiro lançou, em 2011, a campanha "Rio de Janeiro, marca registrada do Brasil". A iniciativa comprova que a criação de uma cidade-marca serve como atrativo para novos negócios, como no caso da marca-Rio, reinventada frente aos megaeventos no início do século XXI. Sede dos eventos Rio 92, Rio+20, Jornada Mundial da Juventude e dos megaeventos Copa do Mundo e Jogos Olímpicos, a cidade ganhou mais reconhecimento, visibilidade nacional e internacional, cidade que marca quem a visita e quem nela mora, com toda sua exuberância. O Rio representa um símbolo brasileiro sob a ótica da metrópole contemporânea.

O sintagma "Rio de Janeiro" reuniria, então, uma marca territorial e uma marca cultural: ser carioca, ser do Rio, morar no Rio; visitar o Rio implica status e valor, fazendo da cidade uma marca-exportação. Neste convívio entre marca territorial e marca cultural, situam-se aspectos econômicos de importante grau 
de investimento, como ações que estimulam o turismo, políticas de segurança, a preservação do meio ambiente e do patrimônio e o incentivo à educação. Sem contar que o Rio saltou de marca territorial, geográfica, para uma espécie de marca corporativa, como espaço de oferta de oportunidades de negócios e lazer em seu cotidiano urbano.

A cidade do Rio foi a primeira do mundo a receber o título de Patrimônio Cultural da Humanidade, conferido pela Unesco em 2012. Patrimônio cultural, grosso modo, é um conjunto de bens e valores materiais e imateriais que pertencem e são compartilhados por todos, unindo o passado ao presente pelo fio fino e flexível, mas resistente, da memória. Para ostentar tal título, a cidade-marca Rio teve reconhecido seu legado cultural, sua relevância universal e a identidade de seu povo, que podem e devem ser usufruídos e preservados por todos.

No entanto, esse processo de construção passou por momentos de representação da violência na cidade. As representações que hoje são feitas do homem urbano, das instituições que o cercam e da violência são, em boa parte, construídas ou reelaboradas pelos meios de comunicação de massa (MOSCOVICI, 2003, p. 33). Esses discursos, de ampla visibilidade, nomeiam e classificam as práticas sociais, produzindo significados diversos. Nosso foco ao analisar as representações da cidade nas narrativas da TV estrangeira, desloca-se das estruturas narrativas para o estudo das relações estabelecidas pela produção de sentidos no ato de narrar, já que tais discursos muitas vezes orientam as práticas sociais (CERTEAU, 1994, p. 201).

Principal destino turístico do Brasil (BRASIL, 2013), o Rio é representado em todo o mundo por uma série de características da ordem do belo e por uma variedade de questões ligadas à violência. Reconhecida como uma cidade de festas, lugares paradisíacos e com um povo sorridente, o Rio de Janeiro é comumente associado a eventos como o Réveillon e o Carnaval. Em ambos, a festa e a violência nutrem narrativas populares e midiáticas que exercem um papel de construção e controle importante nas representações sociais. Os dois documentários sobre turismo no Brasil e no Rio de Janeiro aqui analisados 
foram feitos por estrangeiros para estrangeiros. Veiculados pela tevê, foram produzidos em diferentes momentos do processo de construção da Marca Rio: o estadunidense 1000 places to see before you die, em 2007; e o britânico Brazil with Michael Palin, transmitido em 2012.

\section{Rio de Janeiro: dos simulacros urbanos à favela civilizada}

Os documentários mostram visões do Rio de Janeiro em momentos distintos da construção de sua marca: em 2007, a cidade passava por um momento no qual as representações de violência na mídia eram constantes e construíam uma atmosfera de medo, ligada, especialmente, ao tráfico e à favela. Já em 2012, após diversos esforços (ações governamentais e mercadológicas) para a construção da Marca Rio, a favela passa a ser parte do "ser carioca", trazendo um novo elemento de consumo turístico para a cidade.

Em 1000 places to see before you die, o casal Albin e Melanie Ulle, seguindo o livro-guia homônimo, chega ao Rio de Janeiro após uma expedição na Amazônia. Dos 43 minutos e 34 segundos de programa, 20 minutos (quase metade) foram dedicados ao Rio, em sua mais clássica forma clichê para o consumo turístico: o locutor, em português, fala da "cidade maravilhosa" e apresenta suas belezas naturais: praias e duas mulatas sambando em contra-plongée, evidenciando-se os traseiros das dançarinas, que chacoalham freneticamente.

A beleza da cidade e o físico dos habitantes são destacados desde as narrativas fundadoras (Carta de Caminha, por exemplo), tal como nos aponta Amancio (2000, p. 29) "O Brasil pré-colonial evoca retrospectivamente uma mitologia da sedução do trópico, com sua paisagem paradisíaca e sua gente sensual e receptiva [...] Utopia, mito, miragem, febre de exotismo, é todo um repertório conceitual que vai se projetar na visão das Américas como uma infância da humanidade.".

Tem-se o que o autor chama de "Filiação Pero Vaz", isto é, a "figura do viajante que vive in loco a relação de alteridade, o narrador, o cronista. [...] Corresponderá à experiência vivida do estrangeiro e as representações que seu 
olhar legitima, num processo de seleção por rejeição ou afinidade." (Ibid., p. 33). O autor salienta que o cinema é tal como podemos ver na TV:

\begin{abstract}
Há sempre um estrangeiro na trama para estabelecer os limites e a prerrogativa de um determinado ponto de vista, de um recorte que se explicita nas representações da alteridade. Colocar na tela um outro povo é tarefa que exige uma negociação narrativa, plástica, sonora. Mesmo o documentário, campo maior da evidência da "verdade" na tradição cinematográfica, recorre a intermediações dessa natureza na representação do Outro (loc. cit.).
\end{abstract}

Essa narrativa da experiência é feita por um jovem casal recém-casado, selecionado entre 900 concorrentes. Pessoas "comuns" para viver "a lua de mel perfeita", de acordo com o roteiro proposto no livro ${ }^{5}$. Hospedam-se no Copacabana Palace, que encanta os viajantes. "Isso é tudo o que eu quero nesse mundo", diz Melanie em frente à banheira de hidromassagem com vista para o mar. Albincompleta: "Nós nunca deixaríamos o quarto". Philip Carruthers, gerente do hotel entrevistado pelo programa, salienta a importância histórica do local, a qual ganha ainda mais força quando exibidos os quadros de fotos de celebridades que já se hospedaram lá. Melanie acrescenta: "É um quarto de uma estrela de cinema" (1000 PLACES, 2007).

A segunda parada do programa é a praia de Ipanema (identificada como Beloso Beach), apresentando uma das imagens-clichê da cidade: uma tomada do morro Dois Irmãos durante o pôr do sol - com a contra-luz não é possível ver a favela do Vidigal. Pessoas são filmadas no mar, escolhendo biquínis, praticando esportes, tomando sol, conversando, em uma típica "'paisagem do ócio', fornecida pela ideia de não exigência do trabalho, a visão consumidora do deleite tropical, da generosidade da flora, da fauna e dos nativos, [nas quais] projetam-se as fantasias idílicas europeias de várias gerações" (AMANCIO, 2000, p. 29). A praia é apresentada pelo narrador do episódio como "o palco da vida brasileira", que descreve ainda a relação das mulheres com os biquínis e as cangas e também o 
futevôlei, esporte que nasceu nas areias do Rio de Janeiro. "Todo mundo parece bonito", diz um estrangeiro entrevistado (1000 PLACES, 2007).

O destino seguinte é o bar Garota de Ipanema, frequentado por Vinícius de Moraes e Tom Jobim e onde, segundo o garçom entrevistado, a música homônima foi composta. Trata-se de mais uma referência a um dos clichês da cidade, tendo em vista que essa foi a música mais executada no mundo durante anos, a segunda mais executada da história6. "Nós somos um dos bares mais famosos do mundo", gaba-se o entrevistado. Em seguida, a Feira Hippie de Ipanema, com seu artesanato, é destacada como o melhor local para se encontrar produtos típicos brasileiros. Mais um estrangeiro é entrevistado, informando que era sua terceira visita ao país (Ibid.).

Mostra-se o casal seguindo para o Corcovado em uma visita "ao símbolo icônico do Rio: o Cristo Redentor". Segundo Amancio (2000),

Essencialmente aéreas, as vistas introdutórias do Rio compõem o mais imediato leque de clichês sobre a cidade. Esta facilidade de composição plástica, possibilitada pela exuberante coreografia, estabelece com a presença do mar - a Baía de Guanabara ou as praias oceânicas - um conjunto do qual a natureza tropical parece se nutrir para um efeito de espetacularidade. A natureza emoldura o nicho urbano e the dá substância pictórica (p. 147-148).

Albin (1000 PLACES, 2007) então diz que a estátua do Cristo Redentor é:

[...] definitivamente um dos 1000 lugares que você deve ver antes de morrer, penso que principalmente porque a maioria de nós é familiar a ela, é uma das mais conhecidas imagens ao redor do mundo, mas vê-la em uma foto ou livro não faz justiça a ela, você tem que vir ao Rio e vê-la pessoalmente. 
De lá os dois seguem para o Pão de Açúcar. O guia conta um pouco da história da cidade, como foi "descoberta". À noite, o programa turístico é o samba, apresentado como "a dança característica do Brasil, o sensual samba, uma apimentada explosão rítmica afro-brasileira originária das ruas de regiões humildes [the working-class streets] do Rio de Janeiro. É samba a todo tempo durante o carnaval, uma celebração de gala que rendeu ao Rio a reputação de melhor cidade de festa do mundo", explica o guia (Ibid.). É a primeira vez no episódio que vemos pessoas andando de ônibus, associando-as às "workingclass streets". E, apesar de a visita ser na quadra da Escola de Samba Unidos de Vila Isabel, localizada no bairro de Vila Isabel, a indicação ao telespectador é que a agremiação fica em Ipanema. Além disso, a música de fundo é um samba para reconhecimento estrangeiro, que usa instrumentos como o teclado (não tradicional das escolas).

Enquanto o narrador explica que o desfile é um negócio sério no Brasil, Albin e Melanie são recebidos pelo Rei Momo. Uma passista esclarece que o samba "é a única forma de ver pessoas pobres e ricas juntas se divertindo". Melanie afirma ter entendido, neste momento, o orgulho de ser brasileiro e o casal enfatiza a felicidade de ter estado no país e a vontade de voltar (1000 PLACES, 2007).

A construção da cidade perfeita para consumo turístico passa, entre outras questões, pela exclusão da favela de seus cenários e centralização das atividades em bairros da zona sul (ainda que o samba, por exemplo, seja na zona norte). As narrativas em análise produzem uma simplificação da realidade urbana, controlam e/ou excluem a exibição das diferenças e do inesperado, negam os aspectos contraproducentes da vida, produzindo simulacros para consumo (BAUDRILLARD, 1991), um consumo alheio aos problemas da cidade. Segundo Silva e Manhas (2014):

Mas isso não torna o simulacro uma ferramenta da irrealidade: o simulacro não se opõe ao real; o real dá base para a criação do simulacro, e este, por sua vez, potencializa o real, criando um novo 
conceito de realidade, uma simulação diferente do objeto inicial, porém também real, a partir do ponto em que essa nova realidade se torna melhor que o real e passa a ter mais importância do que sua realidade original. Passa a se tornar o que Baudrillard (1991) chamou de Hiperreal (p. 152).

O outro programa analisado aqui foi gravado cinco anos depois. Brazil with Michael Palin busca um tom mais jornalístico e a tentativa de construir uma nova verdade sobre a cidade, ainda que certos temas sejam baseados em clichês. A principal diferença está na inclusão da favela no roteiro, excluída do documentário anterior. Inclui-se uma favela "civilizada", "pacificada", parte de uma cidade que tenta "se unir" e integrar o pobre, apesar dos problemas sociais que permeiam o país. Nesse sentido, é possível perceber os esforços para construção do Rio de Janeiro enquanto marca-destino pela experiência única que proporciona, pela busca por diferenciação e por oferecer aos visitantes "uma garantia de experiências de qualidade, [que] consolida e reforça a conexão emocional entre os visitantes e o destino e reduz os custos de busca e os riscos percebidos pelo visitante" (GARCÍA; GÓMEZ; MOLINA, 2013, p. 112).

Dos pouco mais de 58 min de episódio, cerca de 40 são dedicados ao Rio. Antes Michael Palin passa por Minas Gerais. Ao chegar à capital carioca, Palin exalta seu tamanho (6,5 milhões de habitantes) e beleza, qualificando-a como "uma das grandes capitais do mundo". A alcunha "cidade maravilhosa" também é mencionada em português, assim como as imagens aéreas e das praias são destaque. O Cristo Redentor é o primeiro desses destaques entre os pontos turísticos. O foco deste episódio, é a história da construção do monumento.

Bel Noronha, bisneta de Heitor da Silva Costa, o responsável pelo desenho e construção da estátua, é, então, entrevistada. No trajeto ao Cristo, com especial destaque ao trem e à paisagem no entorno, Bel (BRAZIL, 2012) salienta que a estátua representa mais que o espírito carioca, mas o espírito nacional, "porque o dinheiro para erguer a estátua veio de todo Brasil". 
Agora o tema é futebol. A segunda parada turística é no campo do Fluminense, "um dos mais famosos clubes do Rio" (Ibid.), em Laranjeiras, na zona sul da cidade. Nesse momento, Palin convida Tim Vickery, jornalista esportivo inglês, para acompanhá-lo. Com uma sede de mais de 100 anos e uma bela vista da Floresta da Tijuca ao fundo, o clube é apresentado de uma forma nobre, como parte da história do futebol brasileiro ("o primeiro jogo do Brasil aconteceu aqui"). O futebol brasileiro é apresentado como "mágico", as "habilidades individuais" dos jogadores são comparadas àquelas "necessárias à sobrevivência dos garotos pobres" e a entrada do Maracanã é exibida, porém, não é identificada.

Palin comenta que as imagens clássicas do Rio são clássicas do Brasil, tais como o Pão de Açúcar, o Cristo Redentor e as praias de Copacabana e Ipanema. Imagens constantemente repetidas, segundo o apresentador, especialmente no momento em que o Rio iria sediar a Copa do Mundo em 2014 e as Olimpíadas em 2016. "A imagem do Rio é de uma cidade legal, de um colorido glamoroso (colorful glamorous fun city)." Entretanto, haveria um outro lado: as favelas, onde cerca de um milhão de pessoas pobres vive. Segundo Palin (Ibid.):

O grande desafio na cidade agora é como curar essa divisão, como fazer a cidade única, como tirar o poder das drogas das favelas e devolvê-lo às pessoas que vivem lá. Se isso for bem sucedido, haverá profundas implicações no futuro da cidade.

Michael Palin passa, então, à política de pacificação da cidade, apresentando o BOPE (Batalhão de Operações Policiais Especiais). O treinamento pesado e a eficácia do combate aos traficantes são exaltados pelo apresentador. No entanto, para ressaltar a política aproximativa do projeto, Palin (Ibid.) entrevista "uma das seis mulheres na tropa de elite" - a capitã Melissa Neves, que explica seu trabalho: trata-se, principalmente, de retomar o espaço tomado pelo tráfico para devolvê-lo ao Estado, mas também de tentar estabelecer relações com a comunidade, envolvê-los com a promoção de eventos e atividades, e tentar 
fazer a comunidade livre novamente. Ela diz que o fato de ser mulher auxilia a comunidade a ver o BOPE como uma força menos agressiva, especialmente entre as crianças, que ficam felizes com a presença feminina.

O investimento em infraestrutura que acompanha a pacificação é destacado com o passeio no teleférico do Morro do Alemão, no subúrbio do Rio, uma das áreas consideradas mais violentas da cidade. Um representante da prefeitura da cidade acompanha Palin no trajeto, enfatizando os projetos da prefeitura nas áreas de infraestrutura, moradia, geração de renda para os moradores do local para fazer a favela "tão maravilhosa quanto a cidade". O apresentador pergunta a um morador do Alemão sobre a vida antes da pacificação. O entrevistado responde que as "coisas não estão perfeitas" (pois convivem mais com a violência), mas que estão "na direção certa". Palin pergunta ainda se ele já carregou alguma arma. O entrevistado responde que nunca esteve envolvido diretamente com o tráfico, mas, como tinha amigos envolvidos, já havia, sim, carregado uma (BRAZIL, 2012).

Para contrapor os benefícios do projeto de pacificação, Michael (Ibid.) visita o Complexo da Maré, ainda não pacificado à época da gravação do episódio, afirmando: "É perigoso andar por uma favela não pacificada, a menos que você conheça alguém do lugar". É nesse momento que Michael Palin apresenta Luke Dowdney, inglês que desenvolve o projeto social "Luta pela paz", ligado ao esporte na favela - mais especificamente ao boxe. Dowdney ressalta a presença de gangues e a violência, inclusive entre crianças, que andam armadas. Palin, por sua vez, destaca o sucesso do projeto do inglês, que engloba esporte e educação.

Pode-se notar a importância dada à presença do governo do Estado e da polícia, relacionando-as diretamente às "melhorias" ocorridas nos últimos anos na comunidade. A ideia de uma Instituição, de um poder centralizado, somado à monopolização da força e da violência física se destacam nesse sentido, tal como proposto por Elias (1994), como parte de um processo civilizador moderno. E, embora o autor tenha analisado esse processo na 
formação das cortes europeias - quando a nobreza belicosa é substituída por uma nobreza domada - com a transformação de guerreiros em cortesãos é possível perceber as similaridades do estudo com as representações do episódio em questão, na busca de uma conduta voltada para a regulação, para a "civilidade". Podemos também inferir que há uma ideia do esporte como um "processo civilizador", ainda no sentido proposto por Elias, como um desejode assimilação, por parte das classes mais baixas, do que seria considerado um "bom modo de vida", e da escola como instituição constituidora de cidadãos aptos para o trabalho e a mudança de vida que devem almejar, segundo o programa.

Após quase 20 minutos de apresentação do projeto de pacificação e da explanação dos projetos sociais, Palin volta à praia para entrevistar a autora do livro How to be a carioca, a americana Priscilla Ann Goslin. Os dois falam, por exemplo, da influência do tempo chuvoso - que acompanha Palin por todo episódio - sobre o carioca: "eles evaporam das ruas, basicamente [...], mas cariocas nunca ficam deprimidos. [...] Vai ser tão bom quando a chuva parar que eles vão voltar para a praia". Ela salienta, ainda, que os cariocas ignoram a presença de coisas ruins como a violência, mudando de assunto, para falar, por exemplo, sobre futebol (BRAZIL, 2012).

O apresentador segue, então, para a suíte presidencial de um motel, onde encontra Luhanna Melloni, apresentadora de um programa de TV sobre sexo, para falar sobre a liberdade sexual do brasileiro. Ela apresenta o local, os brinquedos sexuais, enquanto o inglês parece desconcertado, destacando que a cidade tem uma atitude aberta com relação aos direitos das minorias sexuais. A visita seguinte é no centro do programa "Rio Sem Homofobia". Palin entrevista a coordenadora do programa, Marjorie Mach, que explica a diferença entre transexuais e travestis. De lá, seguem para a Parada do Orgulho Gay, em Copacabana. Palin comenta "se viajar se trata de olhar e aprender, o Brasil não é um mau lugar para se começar. Há um impressionante trabalho de tolerância aqui" (Ibid.). 


\section{Uma marca em construção}

É possível perceber uma mudança nas narrativas que constroem o Rio de Janeiro enquanto marca-destino: de um simulacro para a produção da "segurança da expectativa preenchida." (JAGUARIBE, 2011, p. 6). Partimos da hipótese de que essa mudança está inserida em um projeto de branding que visa a pôr o Rio de Janeiro no centro do turismo internacional e da realização de megaeventos, por intermédio da construção da ideia de "cidade ideal". Jaguaribe (2011) diz que:

\footnotetext{
O crucial no processo de branding é vender uma imagem da cidade para que ela possa ser a recipiente de recursos, investimentos, turismo e ganhos econômicos. Cada cidade terá que inventar e apostar nas suas próprias estratégias de branding levando em conta uma adequação entre seus repertórios e seus slogans. No caso do Rio de Janeiro, famosamente alcunhada de "cidade maravilhosa", a busca pelo branding convidativo se defronta com legados contraditórios (p. 3-4).
}

Nesse sentido, o contraste social e a violência das favelas, ícones do imaginário global, passam a ser reinventados. Essa reinvenção passa por um ideal civilizatório moderno (ELIAS, 1994), constrói contextos de alteridade e cria mapas nacionais que não levam em conta as subjetividades, mas que representam o projeto político, muitas vezes arbitrário, de transformar o Rio de Janeiro na nova capital da cartografia pós-nacional, que seria fundada a partir de tentativas de organizar a vida social em torno do turismo (APPADURAI, 1997).

Essa marca-destino privilegia as praias e um tipo de carioca em detrimento dos bens artísticos, históricos e culturais. Moscovici (2003, p. 34) diz que uma representação, "sendo compartilhada por todos e reforçada pela tradição, ela constitui uma realidade social sui generis. Quanto mais sua origem é esquecida e sua natureza convencional é ignorada, mais fossilizada ela se torna." (idem, p. 41). Nesse sentido, Freitas, Lins e Santos (2013), ao tratarem sobre o uso dos clichês nos megaeventos, dizem que: 
o emocional, imprescindível a qualquer evento. Afinal, como imagens cristalizadas, os clichês são mensagens já consolidadas no imaginário coletivo e, no caso deste estudo, não expressam atributos negativos, embora tendam ao reducionismo das manifestações culturais a que se referem (p. 14).

Temos de considerar, nas narrativas em questão, a necessidade de identificação e criação de empatia com o público, sem perder de vista o olhar crítico sobre a cidade e seus problemas sociais. Salienta-se, contudo, que há uma reconstrução dessas representações para a criação de uma imagem de cidade que seja condizente com o cenário internacional no qual estamos hoje inseridos: o de produção de megaeventos. 


\section{Referências}

1000 PLACES to see before you die - Brazil. Produção de Casey Brumels. Estados Unidos: TLC, 2007.

AMANCIO, T. O Brasil dos gringos: imagens no cinema. Niterói: Intertexto, 2000.

APPADURAI, A. Soberania sem territorialidade. Revista Novos Estudos do CEBRAP, São Paulo, n. 49, p. 33-46, nov., 1997.

BAUDRILLARD, J. Simulacros e simulação. Lisboa, Portugal: Antropos, 1991.

BAUMAN, Z. Medo líquido. Rio de Janeiro: Zahar, 2008.

BRASIL. Ministério do turismo. Anuário estatístico de turismo 2013 (Ano base 2012). Disponível em: < http://www.dadosefatos.turismo.gov.br/dadosefatos/ anuario/downloads_anuario/Anuario_Estatistico_de_Turismo_-_2013_-_Ano_ base_2012_-_Versao_dez.xlsx>. Acesso em: 30 jan. 2015.

BRAZIL with Michael Palin. Produção de John Paul Davidson. Reino Unido: BBC, 2012.

BOSI, E. Memória e Sociedade. São Paulo: Cia das Letras, 2009.

CERTEAU, M. A invenção do cotidiano 1: artes de fazer. Petrópolis: Vozes, 1994.

ELIAS, N. O processo civilizador. 2. ed. Rio de Janeiro: Jorge Zahar, 1994.

FRANZ, M. A inquietude da memória. Florianópolis: Cidade Futura, 2006.

FREITAS, R. F. ; LINS, F.; SANTOS, M. H. C. Brasil em 8 minutos: a (re)apresentação do país na cerimônia de encerramento da Olimpíada 2012. In: XXII COMPÓS, 
2013, Salvador, BA. Anais... Salvador: Vila Galé, 2013. Disponível em: <http:// compos.org.br/data/biblioteca_2035.pdf>. Acesso em: 09 fev. 2014.

GARCÍA, J. A.; GÓMEZ, M.; MOLINA, A. Posicionamiento de marcas-destino: una aplicación en cinco regiones españolas. INNOVAR: Revista de Ciencias Administrativas y Sociales, vol. 23, n. 50, p. 111-127, out-dec., 2013.

JAGUARIBE, B. Imaginando a cidade maravilhosa: modernidade, espetáculo e espaços urbanos. In: XX COMPÓS, 2011, Porto Alegre, RS. Anais... Porto Alegre: UFJF. Disponível em <http://www.compos.org.br/data/biblioteca_1694.doc>. Acesso em: 09 fev. 2014.

JANSSON, J. ; POWER, D. (Orgs). Image of the city: urban branding as constructed capabilities in Nordic city Regions. Oslo: Departamento da Geografia Social e Econômica da Uppsala University, 2006.

JORNAL O GLOBO, Rio de Janeiro, p. 14, 23 out., 2014.

MAFFESOLI, M. La part du diable: précis de subversion postmoderne. Paris: Flammarion, 2002.

MARTÍNEZ, S. I. F. Sistema de gestión comunicacional para la construcción de una marca ciudad o marca país. Signo y Pensamiento, Bogotá, v. XXVI, n. 51, jul-dez, 2007.

MOSCOVICI, S. Representações sociais: investigações em psicologia social. Petrópolis: Vozes, 2003.

SÁNCHEZ, F. A reinvenção das cidades, para um mercado mundial. Chapecó: Argos, 2010. 
SILVA, L. F. C.; MANHAS, A. C. B. S. A percepção do espaço urbano dentro do simulacro: um estudo de caso. Revista Paranaense de Desenvolvimento, Curitiba, v. 35, n. 126, p. 147-159, jan-jun., 2014.

SIMMEL, G. Philosophie de la modernité. Paris: Payot, 2004.

STEWART, S. Two innocents abroad, with TV cameras in tow. The New York Times, Nova York, 29 mar. 2007. Disponível em: < http://www.nytimes. com/2007/03/29/arts/television/29stew.html?_r=1\&>. Acesso em: 11 fev. 2015.

VIANNA, Luiz Fernando. 'Garota de Ipanema' é a segunda canção mais tocada da História. Jornal O Globo, Rio de Janeiro, 3 mar. 2012. Disponível em: < http://oglobo.globo.com/cultura/garota-de-ipanema-a-segunda-cancao-maistocada-da-historia-4340449>. Acesso em: 30 jan. 2015.

submetido em: 04 ago. 2015 | aprovado em: 05 set. 2015 